\title{
Educação superior do campo: Reflexões e críticas da formação de professores no curso de Licenciatura em Educação do Campo Ciências da Natureza e Matemática na UFMA
}

Higher education in the field: Reflections and criticisms of teacher training in the Bachelor's Degree in Rural Education Sciences of Nature and Mathematics at UFMA

Diana Costa Diniz Evandro Ghedin

Resumo: Neste artigo apresentaremos a experiência de formação de professores no Curso de Licenciatura em Educação do Campo Ciências da Natureza e Matemática na Universidade Federal do Maranhão - UFMA. Sua construção é resultante dos estudos de doutoramento no programa de Pós-graduação em Educação em Ciências e Matemática da Rede Amazônica de Educação em Ciências e Matemática (Reamec). Ele resulta de pesquisa bibliográfica e documental na análise dos dados com fundamentação no materialismo histórico e dialético. Pretendeu-se neste trabalho discutir a formação de professores no contexto da expansão da Educação Superior do Campo em contraposição a concepção de Educação Rural, arraigada no velho ruralismo pedagógico considerando as mudanças políticas e sociais a partir dos anos de 1990 no Estado Brasileiro.

Palavras-chave: Formação de professores. Educação Superior do Campo. Curso de Licenciatura em Educação do Campo Ciências da Natureza e Matemática.

Summary: In this article we will present the experience of teacher training in the Course of Education in the Field of Natural Sciences and Mathematics at the Federal University of Maranhão - UFMA. Its construction is the result of doctoral studies in the Graduate Program in Education in Science and Mathematics of the Amazon Network of Education in Science and Mathematics (Reamec). It results from bibliographical and documentary research in the analysis of data based on historical and dialectical materialism. The aim of this work was to discuss the formation of teachers in the context of the expansion of Higher Education in the Countryside in opposition to the concept of Rural Education, rooted in the old pedagogical ruralism considering the political and social changes since the 1990s in the Brazilian State.

Keywords: Teacher training. Higher Education in the Countryside. Degree Course in Field Education Natural Sciences and Mathematics.

\section{Introdução}

Este artigo integra os estudos realizados na pesquisa de doutorado no programa de Pós-graduação em Educação em Ciências e Matemática da Rede Amazônica de Educação em Ciências e Matemática (Reamec) sobre a formação de professores no Curso de Licenciatura em Educação do Campo no contexto das políticas educacionais a partir da década de 1990. 
O texto encontra-se organizado em três seções: a primeira traz uma abordagem sobre a formação de professores no contexto da Educação do Campo em contraposição à Educação Rural; na segunda contextualiza o histórico da implantação da Licenciatura em Educação do Campo na UFMA; por último, apresentamos as contradições e possibilidades desta formação como responsável pela oferta da educação pública enquanto direito universal da população camponesa.

\section{A formação de professores no brasil - política de estado?}

No século $X X$, o Brasil país predominantemente rural entrou na década de 1930 marcado por intensas mudanças políticas, econômicas e sociais decorrentes da crise internacional da economia em decorrência de necessidades formativas de profissionais que viessem atender ao projeto educacional do Brasil urbano-industrial em que segmentos da sociedade civil reivindicavam a expansão das oportunidades educacionais foram criadas a Universidade de São Paulo, em 1934, e a Universidade do Distrito Federal, em 1935. A partir da fundação dessas universidades que se organizaram e implantaram as licenciaturas para a formação de professores secundários, estendidas para todo o país pelo decreto-lei n. 1.190, de 4 de abril de 1939.

Os cursos de licenciaturas desse período estavam organizados por meio de uma estrutura curricular seguindo o esquema $3+1$, em que consistia em três anos de estudo dos conteúdos cognitivos ou das disciplinas específicas e um ano de conteúdos didáticos. As práticas formativas contemplava um conjunto de disciplinas científicas e pedagógicas como uma atividade meramente instrumental, visando à solução de problemas através da aplicação de teorias, métodos e técnicas denominado modelo da racionalidade técnica que separa teoria e prática, reflexão e ação, conteúdo e forma, ensino e pesquisa.

Analisando a história da formação de professores no contexto brasileiro Saviani (2011) identifica que no período de 1939 a 1990 a base epistemológica das políticas públicas de formação de professores constituiu-se numa concepção pragmática e tecnicista nos cursos de licenciatura com a predominância de 
conhecimentos a área disciplinar específica caracterizada pela existência de dois modelos que emergiram no decorrer do século XIX:

\begin{abstract}
"modelo dos conteúdos culturais-cognitivos para o qual a formação de professores se esgota na cultura geral e no domínio específico dos conteúdos da área de conhecimento correspondente à disciplina que o professor irá lecionar. Considera-se que a formação pedagógico-didática virá em decorrência do domínio dos conteúdos do conhecimento logicamente organizado, sendo adquirida na própria prática docente ou mediante mecanismos do tipo "treinamento em serviço". Do outro lado se contrapõe o modelo segundo o qual a formação de professores só se completa com o efetivo preparo pedagógico-didático. Em consequência, além da cultura geral e da formação específica na área de conhecimento correspondente, a instituição formadora deverá assegurar, de forma deliberada e sistemática, por meio da organização curricular, a preparação pedagógico-didática sem o que não estará, em sentido próprio, formando professores. Eis o que eu denomino de "modelo pedagógico-didático de formação de professores". Saviani (2011, p.08 e 09)
\end{abstract}

Em 1990, realizou-se em Jomtien (Tailândia), a Conferência Mundial de Educação para Todos financiada pela UNESCO (Organização das Nações Unidas para a Educação, a Ciência e a Cultura), UNICEF (Fundo das nações Unidas para a Infância), PNUD (Programa das Nações Unidas para o Desenvolvimento) e Banco Mundial. O evento teve como finalidade consolidar um grande projeto mundial de "Educação para Todos", tendo como principal estratégia a satisfação das necessidades básicas de aprendizagem. Os acordos firmados pelos países subdesenvolvidos (Brasil, Bangladesh, China, Egito, Indonésia, Índia, México, Nigéria e Paquistão) visavam à elevação da qualidade do ensino, a empregabilidade, a partir de fatores determinados pelo Banco Mundial entre os quais a qualificação dos profissionais da educação.

No que diz respeito à reflexão sobre a formação de professores é necessário compreender [...] as respostas que o governo brasileiro vem dando às novas demandas por educação e, consequentemente, da formação de professores, por meio da legislação e das políticas públicas a partir de 1990 [...] (KUENZER, 1999, p.175). Inicialmente destaca-se que a conjuntura política do início da década de 90 demarca a intensidade da presença do ideário neoliberal assumido como referência fundamental, [...] no Brasil, na América Latina e 
Caribe e no mundo, como elemento de um processo de mundialização do capital, modificando nossas vidas e interferindo no planejamento e realização [...] das políticas educacionais (MELO, 2004, p. 27). No setor educacional foram implementadas intensas reformas educativas, com o objetivo de adequar esse sistema ao processo de reestruturação produtiva e aos novos rumos do Estado.

As reformas atingiram todas as áreas do Estado brasileiro. Tais reformas surgem oriundas das mudanças pelas quais passou o mundo do trabalho, da reestruturação produtiva e das crises sistemáticas do capitalismo e as profundas transformações ocorridas em termos mundiais que determinariam uma nova geopolítica e, consequentemente, o surgimento de novas demandas para o desenvolvimento social e econômico. Em relação à educação, elas afetaram todos os níveis e modalidades de ensino, inclusive a formação dos educadores e as suas políticas de financiamento. Essas mudanças alteraram significativamente a formação e o lócus onde se realizava. Este interesse pode ser observado em Freitas:

Também à época a qualidade da educação e da escola básica passa a fazer parte das agendas de discussões e do discurso de amplos setores da sociedade e das ações e políticas do MEC, que buscava criar consensos facilitadores das mudanças necessárias na escola Básica, principalmente no campo da formação de professores. Tais mudanças encontram no processo de elaboração e aprovação da LDB, em 1996, o marco da institucionalização das políticas educacionais que, e gestadas desde o início da década, se aprofundam nos anos de FHC e fundamentam, posteriormente o Plano Nacional de Educação (PDE) do governo, em contraposição ao PNE da sociedade. (FREITAS, 2007, p.25)

As mudanças proposta para a formação de professores a partir da Lei de Diretrizes e Bases da Educação Nacional - LDB (Lei 9394/96) trouxeram avanços, mas expressaram contradições em todos os âmbitos do sistema educacional, tendo em vista imprimir novos rumos às práticas educativas e formativas do educador de forma que, tais ajustes, passariam, também, por uma nova ordem de desenvolvimento de habilidades competências. A Lei no capítulo que trata dos profissionais da educação art. 62 estabelece que:

A formação de docentes para atuar na educação básica far-seá em nível superior, em curso de licenciatura, de graduação 
plena, em universidades ou institutos superiores de educação, admitida, como formação mínima para o exercício do magistério da educação infantil e nas quatro primeiras séries do ensino fundamental, oferecida em nível médio, na modalidade normal. (BRASIL, 1996).

Por outro lado, no que concerne a questão do direito a educação das populações do campo a LDB 9394/96 representou um avanço à medida que em conformidade com a constituição de 1988, assegurou o direito público à educação básica, contemplando todos os níveis e modalidades de ensino, com a possibilidade de reposicionar a educação do campo no cenário da política educacional, conforme consta no seu artigo primeiro determinando que:

"A educação deve abranger os processos formativos que se desenvolvem na vida familiar, na convivência humana, no trabalho, nas instituições de ensino e pesquisa, nos movimentos sociais e organizações da sociedade civil e nas manifestações culturais".

Além disso, reconhece a diversidade sociocultural e o direito à igualdade e a diferença, sinalizando uma formação básica que garanta as especificidades regionais e locais assim como a organização do trabalho pedagógico, explicito nos artigos:

Artigo 26 - "Os currículos do ensino fundamental e médio devem ter uma base nacional comum, a ser complementada, por uma parte diversificada, exigida pelas características regionais e locais da sociedade, da cultura, da economia e da clientela".

Artigo 28 - "Na oferta da educação básica para a população rural os sistemas de ensino proverão as adaptações necessárias à sua adequação, à peculiaridade da vida rural e de cada região, especialmente: - conteúdos curriculares e metodologia apropriada às reais necessidades e interesses dos alunos da zona rural; - organização escolar própria, incluindo a adequação do calendário escolar às fases do ciclo agrícola e às condições climáticas; - adequação à natureza do trabalho na zona rural".

Assim, nesse contexto, os movimentos sociais e sindicais começam a se destacar tanto na luta pela terra, quanto pela educação ao reivindicarem um projeto de formação de professores fundamentado numa forma de escola e de ensino emancipatória que se constitui a partir da tríade campo, política pública e educação, ou seja, uma educação para além do capital apoiada em uma formação qualificada dos profissionais da educação comprometida com o futuro 
do nosso povo, crianças, jovens e adultos. Em outras palavras, para que ocorra a construção de um sistema educacional significativamente diferente, é preciso considerar " $[\ldots]$ a totalidade das práticas político-educacional-culturais, na mais ampla concepção do que seja uma transformação emancipadora [...]" (MESZÁROS, 2005, p. 57).

\section{A Formação de professores: da Educação Rural à Educação do Campo}

A educação rural, tal qual foi concebida, era destinada a uma minoria, embora a maioria da população brasileira vivesse na zona rural, uma vez que o Brasil tinha uma base de produção eminentemente agrária. No âmbito da legislação, essa modalidade de educação sequer foi mencionada nos textos constitucionais até 1889 , resquícios de uma sociedade cujas matrizes históricas estavam vinculadas a um modelo econômico de base agrária que se apoiava no latifúndio e no trabalho escravo (BRASIL, 2004).

No Brasil consolidou-se um paradigma em que se apoia a visão tradicional do espaço rural como sinônimo de atraso, com os indicadores sociais mais baixos, resultantes do descaso histórico dos sucessivos governos brasileiro com essas áreas: pobreza, violência, desemprego, falta de acesso à educação e as demais políticas públicas (saúde, previdência, cultura, moradia, transporte). Para Leite (2012, p.14):

A educação rural no Brasil, por motivos socioculturais, sempre foi relegada a planos inferiores e teve por retaguarda ideológica o elitismo acentuado do processo educacional aqui instalado pelos jesuítas e a interpretação político-ideológica da oligarquia agrária, conhecida popularmente na expressão: "gente da roça não carece de estudos. Isso é coisa de gente da cidade".

Durante décadas buscou-se um crescimento e, para tanto, os governos sempre investiram nos locais onde tinha mais possibilidades desse crescimento, ou seja, nas áreas mais povoadas do país. Todas as investidas no quesito educação e escola para o povo rural, não representaram ações de emancipação e crescimento do sujeito como um ser ativo na sociedade. Dessa forma Calazans enfatiza que 
A educação, que se propõe a ser fator de desenvolvimento, e que, de forma programada, inclui-se numa planificação global, tem de estar atenta às solicitações feitas pelas estruturações específicas já implantadas, equipando-se para uma capacitação específica de quadros; e também voltada para a criação de uma mentalidade tecnológica condizente com a atualização condizente com a atualização do homem no que diz respeito às relações da economia. (CALAZANS, 1993 p.35).

Nos anos 1990, os movimentos sociais do campo mostraram ao governo e à sociedade que a educação do campo nunca foi prioridade do Estado brasileiro. Essa mobilização e organização de movimentos sociais com identidades diversas, representativos de ribeirinhos, quilombolas, sem-terra, extrativistas, trabalhadores rurais assalariados, indígenas que lutam por uma educação do e no campo desencadeou a campanha Por uma educação do campo e para a concretização de uma concepção de Educação do Campo, em contraposição ao conceito de educação rural vigente na história da educação brasileira.

Como afirma Caldart (2010, p. 105):

a gênese da educação do campo é fruto da denúncia de processos de exclusão da terra, da educação, da moradia, da cultura e da vida. É fruto da prática coletiva que, ao denunciar, exercita a participação coletiva e efetiva categorias que são fundantes da política pública orientada para a transformação social.

O primeiro passo para o estabelecimento de um diálogo entre movimentos sociais do campo e o Estado foi a realização do I Encontro Nacional de Educadores e Educadoras da Reforma Agrária - I Enera, realizado em julho de 1997, em Brasília, como o apoio da Universidade de Brasília - UnB, Fundo das Nações Unidas para a Infância (Unicef), Organização das Nações Unidas para a Educação, a Ciência e a Cultura (Unesco) e da Conferência Nacional dos Bispos do Brasil (CNBB). Esse Encontro conduziu à organização, em 28 de julho de 1998, da I Conferência Nacional por uma Educação Básica do Campo, promovida pelo Movimento dos Trabalhadores Rurais Sem Terra (MST), Unicef, Unesco, CNBB e UnB.

A I Conferência Nacional por uma Educação do Campo, explicita no seu texto o sentido da mudança do conceito ao destacar que: 
Utilizar-se-á a expressão campo, e não a mais o usual meio rural, com o objetivo de incluir no processo da conferência uma reflexão sobre o sentido atual do trabalho camponês e das lutas sociais e culturais dos grupos que hoje tentam garantir a sobrevivência desse trabalho. Mas quando se discutir a educação do campo se estará tratando da educação que se volta ao conjunto dos trabalhadores e das trabalhadoras do campo, sejam as nações indígenas, sejam os diversos tipos de assalariados vinculados à vida e ao trabalho no meio rural (KOLLING; NERY; MOLINA, 1999, p. 26)

A realização do I ENERA possibilitou a organização do Movimento Por uma Educação do Campo constituído por movimentos sociais e universidades que passaram a defender o direito à educação em todos os níveis e modalidades. Essa pressão sobre o Estado o levou a tomar medidas políticas educacionais mais efetivas, as quais culminaram com a aprovação do Programa Nacional de Educação na Reforma Agrária - Pronera.

No período de 2 a 6 de agosto de 2004, foi realizada a II Conferência Nacional por uma Educação do Campo também na cidade de Luziânia (GO), organizada pelo MST, CNBB, Unicef, Ministério do Desenvolvimento Agrário MDA / Incra / Ministério da Educação - MEC, Confederação Nacional dos Trabalhadores na Agricultura (Contag) e outras organizações da sociedade civil. Dentre outras bandeiras de luta no texto base reforça-se a necessidade de construir uma política de formação de professores através da criação de cursos de nível superior para atuação nas escolas de educação básica do campo. Em resposta às reivindicações pautadas no referido evento o MEC aprovou e instituiu através da Portaria $n^{\circ}$ 1.374, de 03 de junho de 2003, um Grupo Permanente de Trabalho - GPT ${ }^{1}$ com a finalidade de elaborar uma proposta de formação de professores a partir do acúmulo conquistado pelos movimentos sociais camponeses na elaboração e participação no Pronera, por meio da realização dos cursos de Pedagogia da Terra.

\footnotetext{
1 Em sua composição constam os representantes das Secretarias integrantes da estrutura do Ministério da Educação: Secretaria de Educação Fundamental (SEF), Secretaria de Educação Superior (SESu), Secretaria de Educação a Distância (SEED), Secretaria de Educação Especial (SEESP), Secretaria de Educação Média e Tecnológica (Semtec) e dos Programas Bolsa Escola, Brasil Alfabetizado, e ainda representantes do Instituto Nacional de Estudos e Pesquisas Educacionais (INEP), Fundo Nacional do Desenvolvimento da Educação (FNDE), Coordenação de Aperfeiçoamento de Pessoal de Nível Superior (Capes) e Gabinete do Ministro". (BRASIL, 2003, p.1).
} 
A proposição apresentada em 2005 pelos membros do GPT foi de uma Licenciatura em Educação do Campo considerando vários fatores tais como:

[...] um curso que respondesse às necessidades de fortalecimento e ampliação da oferta da Educação Básica no campo. Por que pensar somente em professores para as séries iniciais, quando os dados indicam a quase ausência de oferta das séries finais do ensino fundamental e de ensino médio? [...] emergiu a discussão sobre a superação do modelo disciplinar na formação docente. Ao final concluiu-se que a formação por área de conhecimento poderia ser um caminho para garantir o funcionamento de salas de segundo segmento do ensino fundamental e médio no campo, constituindo assim uma alternativa em um cenário em que a nucleação e o transporte dos alunos para escolas distantes de suas residências tem sido as únicas possibilidades para a escolarização da população do campo (ANTUNES-ROCHA, 2012, p. 41).

Com esse novo desafio, de construção de uma política de formação de professores diferenciada para a população camponesa foi aprovada pelo MEC em 2006 o Programa de Apoio às Licenciaturas em Educação do Campo (Procampo), Programa que implantou um projeto piloto em quatro Universidades: Universidade Federal de Brasília - UnB, Universidade Federal da Bahia - UFBA, Universidade Federal de Sergipe - UFS e Universidade de Minas Gerais - UFMG (ANTUNES-ROCHA, 2012; CALDART, 2010; MOLINA; SÁ, 2011; MOLINA, 2015; 2017.

A partir das experiências-pilotos e a expressiva demanda de formação de professores dos territórios rurais e com a pressão dos movimentos sociais, o MEC divulgou em 2008 e 2009 realizando chamada pública para a seleção de projetos para que outras instituições ofertassem a Licenciatura em Educação do Campo na modalidade de projeto especial. Uma conquista recente dos movimentos e organizações sociais e sindicais do campo foi à homologação do Decreto $N^{\circ}$. 7.352 de 4 de novembro de 2010, que dispõe sobre a política de Educação do Campo e o Pronera. Outra conquista política importante foi a criação do Fórum Nacional de Educação do Campo (Fonec) criado em evento promovido pela Contag ocorrido em Brasília nos dias 16 e 17 de agosto de 2010.

A partir de 2012 o Ministério da Educação lançou o Edital nº 02/2012, para institucionalização definitiva dos cursos que se materializa com a expansão das Licenciaturas em Educação do Campo em 42 (quarenta e duas) instituições de 
ensino superior na perspectiva promover o estudo, a pesquisa e a reflexão sobre a educação dos povos do campo e o desenvolvimento de metodologias para atender a educação das diversidades territoriais e culturais dos povos do campo. No mapa a seguir é possível identificar a expansão dos Cursos de Licenciatura em Educação do Campo nas instituições de educação superior onde o curso tem sido ofertado no Brasil. Na atualidade estão em execução 44 cursos de LEC, distribuídos em 31 universidades e quatro institutos federais.

FIGURA 01 - Cursos ofertados nas Universidades e Institutos por região

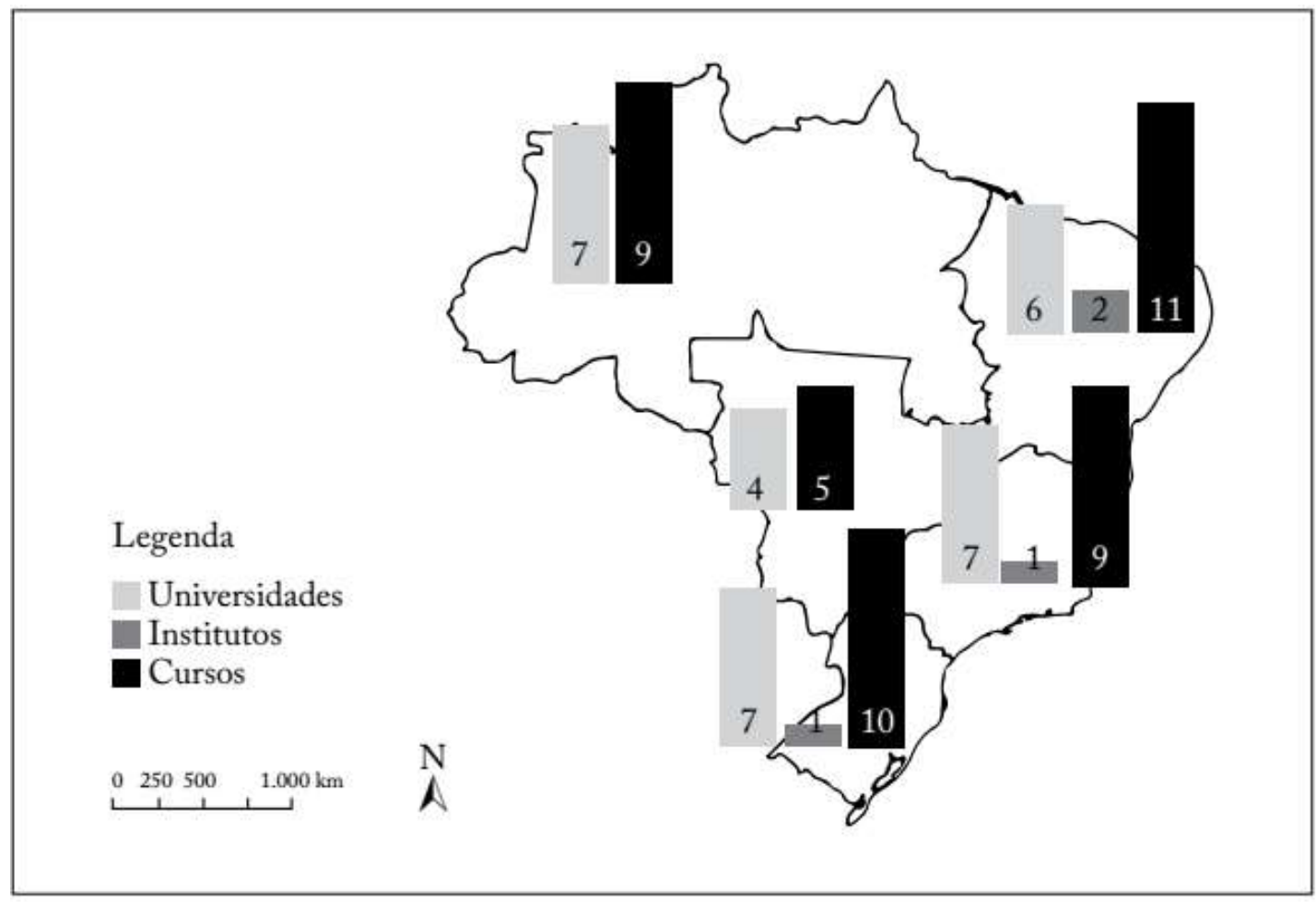

Fonte: Leal et al. (2019, p. 43)

Conforme mapa acima é possível perceber a presença dos cursos de Licenciaturas em Educação do Campo nas cinco regiões brasileiras: Na região Norte (09), Nordeste (11), Centro Oeste (05), Sudeste (09) e Sul (10) totalizando 44 cursos em andamento no país ofertando formação de professores em seis diferentes áreas de conhecimento, quais sejam: Ciências Agrárias (CA), Ciências da Natureza e Matemática (CNM), Ciências da Vida e da Natureza (CVN), Ciências Sociais e Humanidades (CSH), Línguas, Artes e Literatura (LAL) e Matemática, variando conforme as regiões de acordo com sua determinada área de atuação. 
A formação de professores para as escolas do campo: reflexões e críticas de um projeto de formação humana na universidade pública

Nesta seção discutimos a formação de professores no Curso de

Licenciatura em Educação do Campo a partir da experiência da UFMA apresentando o contexto de criação e expansão como política pública, as contradições e possibilidades vivenciadas.

\section{O Curso de Licenciatura em Educação do Campo Ciências da Natureza e Matemática}

O curso tem sua origem no Programa de Apoio à Formação Superior em Licenciatura em Educação do Campo (Procampo), do MEC/ Secretaria de Educação Continuada, Alfabetização e Diversidade (Secad), e foi viabilizado no Maranhão a partir de uma parceria iniciada em 2008 entre a Supervisão da Educação do Campo/Secretaria de Estado da Educação (Seduc), o Comitê Estadual da Educação do Campo e a Pró-Reitoria de Ensino da Universidade Federal do Maranhão.

A proposta de implantação da Licenciatura em Educação do Campo (LEdoC) nessa universidade insere-se num conjunto de ações que executadas no Maranhão, em prol da expansão e da consolidação da política de educação do campo, tanto por instituições federais de ensino superior, UFMA e Instituto Federal de Educação Ciência e Tecnologia (IFMA), Secretaria de Estado da Educação e pelo Comitê Estadual da Educação do Campo, União das Associações das Escolas Família Agrícola (Uaefama), Associação Regional das Casas Familiares Rurais (Arcafar), Federação dos Trabalhadores da Agricultura - Fetaema, Instituto de Colonização e Reforma Agrária - INCRA.

Esse debate chegou em 2007 à UFMA em diálogo com a Supervisora de Educação do Campo (Seduc) Cacilda Rodrigues Cavalcanti e o professor Doutor José de Ribamar Sá Silva vinculado ao departamento de economia da UFMA que conduziu o processo de discussão junto à Pró-Reitoria de Ensino. Foram 
realizados seminários, reuniões de estudo, e encontros de debates na instituição.

Em 23 de abril de 2008 foi lançado pela Secretaria de Educação Continuada, Alfabetização, Diversidade e Inclusão (SECADI/MEC) o Edital $n^{\circ} 2$, que convocava Instituições Públicas de Educação Superior públicas para apresentarem projetos de Cursos de Licenciatura em Educação do Campo para a formação de professores da educação básica nas escolas situadas nas áreas rurais. Esse edital delineava uma proposta bastante específica, apontava e trazia o foco para um processo ensino aprendizagem mediado pela realidade vivida por todos aqueles que participassem do processo formativo.

Com a aprovação do projeto pelo Conselho Universitário (Consun) da UFMA criado pela Resolução $n^{\circ} 111 / 2009$, que passou a funcionar ofertando duas áreas para habilitar profissionais em: Ciências Agrárias, Ciências da Natureza e Matemática, com o propósito de atender às demandas mais urgentes de formação de professores para as escolas do campo e, por outro lado, quanto às características socioeconômicas do estado Maranhão e, particularmente, às condições de produção da vida material predominantes no campo.

O Projeto Político Pedagógico ${ }^{2}$ construído para a Licenciatura em Educação do Campo foi encaminhado para o MEC, conforme o que estabelecia o referido edital. A proposta foi aprovada e, em novembro de 2009 , foi firmado o convênio financeiro entre a UFMA e o MEC. Entre muitas dificuldades financeiras e burocráticas, no primeiro semestre em 2010 foi elaborado e realizado o Processo Seletivo Vestibular Especial (PSVE), em que, no ato da inscrição, o candidato escolhia a habilitação que desejava cursar.

A forma de ingresso foi realizada pelo PSVE através do edital 127/2009 PROEN publicado em junho de 2009 com oferta de 60 (sessenta) vagas para ingresso no $2^{\circ}$ semestre letivo do ano de 2009 , sendo 30 vagas para a habilitação em Ciências da Natureza e Matemática e 30 vagas para Ciências Agrária. As provas foram realizadas em julho e o início das aulas 18 de outubro de 2009. O

\footnotetext{
2 Projeto Político-Pedagógico (PPP) era a denominação utilizada para o referido documento à época de sua elaboração nas versões 2009 e 2014.
} 
número de inscritos foi de 123 candidatos e o número de ingressantes atendeu a meta em cada área.

O perfil da turma contemplou sujeitos pertencentes a diferentes segmentos sociais do campo, em conformidade com o exigido no edital, tais como: filhos/as de agricultores, professores e técnicos que atuam no campo, quilombolas entre outros. Os sessenta educandos selecionados são oriundos de 26 municípios do Maranhão.

Na mesma perspectiva e sem alterar o conteúdo, o Ministério lançou em 2009 o Edital n 09/2009 para submissão de projetos de Cursos de Licenciatura em Educação do Campo para a formação de professores da educação básica nas escolas situadas nas áreas rurais. A UFMA foi contemplada e iniciou o PSVE para implantação de mais uma turma com 60 vagas. Em dezembro foi publicado o edital n³25/2009 - PROEN para realização das provas em fevereiro de 2010 e as aulas iniciaram em maio do mesmo ano.

No que diz respeito ao atendimento houve algumas desistências e as ausências são justificadas por vários motivos, principalmente a dificuldade encontrada nas secretarias municipais de educação com relação à liberação durante as atividades acadêmicas do Curso. As duas turmas concluíram todos os créditos em 2014 com matrícula final de 50 discentes nas turmas 2009 e 38 discentes que ingressaram em 2010.

Em 2012, o Projeto Político Pedagógico foi selecionado através do edital SESU/SECADI/SETEC n 02/2012, para institucionalização definitiva do curso, com áreas de atuação em Ciências Agrárias, Ciências da Natureza e Matemática com previsão de início de atendimento de sessenta ingressantes em agosto de 2013 e em agosto de 2014 sessenta, porém, em função de alguns problemas na tramitação da reformulação do projeto esse calendário não foi possível se efetivar.

Conforme definido no PPP as atividades curriculares estão organizadas em regime de alternância ${ }^{3}$ de Tempos Educativos (Tempo Universidade e

\footnotetext{
${ }^{3}$ Segundo Nosella (1977), a Pedagogia da Alternância surgiu na França como experiência das "Maisons Familiales Rurales" no ano de 1935. Era uma alternativa metodológica de formação profissional agrícola de nível técnico para jovens, inicialmente do sexo masculino, filhos de camponeses que perderam o interesse pelo ensino regular porque este se distanciava totalmente da vida e do trabalho camponês.
} 
Tempo Escola Comunidade), metodologia de organização do trabalho pedagógico articulada com a realidade da escola e comunidade permitindo a unidade teoria e prática, a realização de pesquisas interventivas durante o processo formativo com base nas seguintes dimensões formativas: Estudo de textos básicos relacionados aos componentes curriculares de cada etapa que irão contribuir com a fundamentação teórica, execução e análise das ações de intervenção social; Intervenção social na comunidade e na escola planejadas e executadas coletivamente através de: realização de inventários da realidade e exercícios de pesquisa diagnóstica de processos formativos que constituem a vida social e as relações entre ser humano e natureza, intencionalizados em uma direção emancipatória; Elaboração de registros e reflexões por escrito (Inserção e Observação orientada, Inventário da realidade, Diário de campo individual, Relatórios e/ou Portfólios: reflexão sobre as atividades de inserção social, com base nos estudos realizados.

A Alternância tem na sua origem uma proposta de educação direcionada aos sujeitos camponeses através da articulação das questões pedagógicas associadas ao desenvolvimento econômico, ambiental e humano do campo, como afirma Gimonet (2007, p.120), não basta "suceder-se tempos de trabalho prático e tempos de escola, sem nenhuma relação entre si, para que exista uma formação alternada". Esta organização implica a construção de processos educativos oportunizando um diálogo entre a universidade e os que vivem no e do campo assim como a possibilidade de materializar ações interdisciplinares contemplando a diversidade da população camponesa (TEIXEIRA, BERNARTT: TRINDADE, 2008).

O Projeto Político Pedagógico do Curso de Licenciatura em Educação do Campo Ciências da Natureza e Matemática tem como objetivos:

Compreender, de forma crítica e contextualizada, as relações e processos sociais organizados, a partir da reflexão sobre as diferentes realidades. Promover a integração do aluno com sua comunidade, possibilitando a pesquisa e a construção de projetos e práticas pedagógicas que expressem a história, a cultura e o conhecimento dos educandos, contribuindo para o fortalecimento de sua identidade camponesa. Refletir sobre as relações de gênero, raça e etnia no processo educativo, no âmbito das áreas de reforma agrária e da sociedade. Estudar os 
valores e práticas organizativas das culturas negra, indígena e camponesa, como conteúdos fundamentais para 0 fortalecimento das identidades desses sujeitos. (UFMA, 2014, p.30)

Ainda sobre o PPP os componentes curriculares estão divididos em áreas específicas e interligadas chamadas de Núcleos de Estudos e Atividades. Esses núcleos, compostos por disciplinas curriculares, são concebidos como blocos orgânicos de conteúdos que visam educar o aluno para a sua participação social, tanto do ponto de vista político quanto do ponto de vista técnico. Assim, os componentes curriculares estão organizados em três grandes núcleos, que por sua vez, se estruturam em eixos de formação. São eles

I - Núcleo Básico

II - Núcleo de Estudos Específicos em Ciências Agrárias, Ciências da Natureza e Matemática

III - Núcleo de Atividades Complementares

Tendo em vista essa organização curricular o trabalho pedagógico se amplia para a educação não escolar e para as diversas formas de organização social do campo. Dessa forma a estrutura adotada para o currículo propõe a formação de um licenciado que tem na docência ${ }^{4}$ um caráter particular, a pesquisa como princípio formativo a todos os profissionais formados, independentemente de sua área de formação específica, e a interação e comunicação entre saberes diversos, consolidando uma formação multidisciplinar.

Visando construir um currículo capaz de integrar conhecimento para contextualizar a prática pedagógica, a proposta sinaliza que a organização curricular é orientada pela incorporação da pesquisa como princípio de formação e de intervenção na prática pedagógica, pois,

"uma educação transformadora requer um currículo baseado em pressupostos teóricos da Pedagogia Histórico-Crítica e da Pedagogia Socialista, cujos elementos deverão garantir a

\footnotetext{
${ }^{4}$ Toma como referência a proposta para a formação de educadores defendida pela Associação Nacional pela Formação dos Profissionais da Educação (Anfope), segundo a qual a identidade docente é ampliada pela pesquisa e difusão do conhecimento, rompendo-se com a dualidade entre teoria e prática, e não se limitando a indicar mecanicamente competências e habilidades como perfil do profissional.
} 
identidade do curso, se materializando em ações concretas de intervenção pedagógica na realidade atual das escolas do campo. "(UFMA 2014, p. 52)

A intenção de relacionar teoria e prática, teoria e empiria visando à integração ensino e pesquisa e extensão vem sendo desenvolvida através das seguintes ações em andamento:

O Projeto de Educação Tutorial em Educação do Campo é um grupo de aprendizagem tutorial da Universidade Federal do Maranhão/UFMA, instituído em dezembro de 2010 com 12 bolsistas, voltado para a intervenção políticopedagógica em escolas do campo, envolvendo Cursos de Pedagogia da Terra e de Licenciatura em Educação do Campo voltados para a formação de profissionais para a Educação Básica nas escolas do campo, no estado do Maranhão. As atividades de ensino, pesquisa e extensão são desenvolvidas tanto no âmbito da escola quanto da comunidade, consubstanciando um processo permanente de ação-reflexão-ação.

Em 2010 o curso também foi contemplado pelo edital do Programa Institucional de Bolsa de Iniciação à Docência para a diversidade - PIBID Diversidade. O campo de atuação do programa vem contemplando as escolas do campo, por meio de atividades planejadas e desenvolvidas durante os tempos educativos do curso. As atividades em andamento possibilitaram maior interação entre a UFMA e as escolas de Educação Básica com sede no Estado, a experiência desse diálogo de saberes e aprendizados tem feito significativa diferença tanto na formação dos estudantes da graduação quanto para o cotidiano de trabalho nas escolas envolvidas no subprojeto.

Em 2018 o curso o subprojeto o curso foi aprovado no programa Residência Pedagógica visando favorecer a unidade teoria-prática e o diálogo entre as diversas áreas do conhecimento, resultando, ao mesmo tempo, em ações efetivas de intervenção na realidade e em produção de conhecimento a partir do eixo organização do trabalho pedagógico e da gestão articuladas no curso pelos Estágios em Docência nas Séries Finais do Ensino Fundamental e Estágio em Docência no Ensino Médio e na Educação Profissional de Nível Técnico para responder aos desafios da escola pública no campo. 
Além da formação para a docência destaca-se outra intencionalidade do processo formativo a atuação na gestão de processos educativos escolares e comunitários em conformidade com uma das habilidades do curso para o desenvolvimento de uma consciência para a luta e que sejam sujeitos desse processo, pois,

...os movimentos sociais esperam que um curso como esse possa reparar sujeitos capazes de coordenar processos de formação, mas também de desencadeá-los... Por isso estes mesmos estudantes estão sendo formados também para serem militantes de organizações coletivas com prometidas com projetos de transformação social (ITERRA, 2007, p. 21).

Esta afirmação demonstra claramente a importância da vivência acadêmica no curso de Licenciatura em Educação do campo, a organicidade é uma estratégia dos movimentos sociais com a finalidade de construir relações coletivas visando à transformação das condições de vida da população brasileira, sujeitos do processo educativo em escolas do campo. Portanto, durante o Tempo Universidade os estudantes se organizam em sete grupos de organicidade (Equipe de infraestrutura, Mística, Alimentação, Secretaria, Saúde Esporte e Lazer, Cultura Comunicação Social e Memória e Organicidade) em conformidade com uma das habilidades do curso que é a gestão dos processos educativos para o desenvolvimento de uma consciência para a luta e que sejam sujeitos desse processo.

O Estágio Curricular do curso e as práticas pedagógicas apontam para a necessidade permanente de um movimento dialético - ação-reflexão-ação - sem fugir-se da relação necessária entre a escola do campo e os demais espaços de atuação dos licenciados. Assim, com carga horária de 450h, ao longo de três momentos diferenciados e articulados às atividades de estágio, constituindo-se em:

QUADRO 01: Carga horária do estágio

\begin{tabular}{|l|c|}
\hline ATIVIDADES & CARGA HORÁRIA \\
\hline $\begin{array}{l}\text { Estágio em Docência nas Séries Finais do Ensino } \\
\text { Fundamental }\end{array}$ & 180 \\
\hline
\end{tabular}




\begin{tabular}{|l|c|}
\hline Estágio em Educação Popular no Campo & 90 \\
\hline $\begin{array}{l}\text { Estágio em Docência no Ensino Médio e na Educação } \\
\text { Profissional de Nível Técnico }\end{array}$ & 180 \\
\hline \multicolumn{1}{|c|}{ SUBTOTAL } & 450 \\
\hline
\end{tabular}

Elaboração: Pela pesquisadora a partir do PPC do curso (UFMA, 2014).

Ressalta-se que em setembro de 2014 o curso recebeu a visita dos avaliadores do Sistema Nacional de Avaliação da Educação Superior (Sinaes), lei $\mathrm{n}^{\circ} 10.861 / 2004$ referente ao ato regulatório do curso de licenciatura em Educação do Campo - Ciências da Natureza e Matemática (Código EMEC 123511) com atribuição de conceito três. Quanto ao Exame Nacional de Curso (Enade) a procuradoria institucional da UFMA orientou a Coordenação que os estudantes estariam dispensados de participar.

Neste sentido, o desafio posto ao curso é justamente garantir práticas formativas visando consolidar um trabalho integrado vinculando os conteúdos escolares com os conteúdos da vida, ou seja, precisamos organizar atividades interdisciplinares, com vistas a transformações no funcionamento da escola e em atendimento às demandas da comunidade rural na qual se insere essa escola. A ideia de formação integrada sugere superar a formação dualista e fragmentada caracterizada pela divisão social do trabalho entre a ação de executar e ação de pensar, dirigir ou planejar. Trata-se de superar a redução da preparação para o trabalho ao seu aspecto operacional, simplificado, escoimado dos conhecimentos que estão na sua gênese científico-tecnológica e na sua apropriação histórico social. Ramos (2005; 2006), Freitas (1995).

\section{Considerações finais}

No campo dos direitos sociais, a educação deve ser garantida pelo Estado, devendo, portanto, ser pública, gratuita e com qualidade social. Apesar do reconhecimento de que é direito dos trabalhadores rurais as experiências pedagógicas propostas pelos movimentos sociais camponeses seguem sob a ameaça permanente do Estado entre o dito, o pretendido e o feito. Deve 
constituir-se num processo permanente, sem, contudo, subjugar-se à noção neoliberal de educação, a qual, na atualidade, continua a proclamar a educação para todos, porém, flexibilizando-a, focalizando-a, privatizando-a sob a lógica da relação custo-benefício.

Percebe-se que ao mesmo tempo em que foram anunciadas ações de ampliação da oferta de cursos em contraposição tem-se o corte no orçamento global nas universidades, gerando impasses com relação à consolidação das experiências que se institucionalizaram a partir do edital nº 02/2012.

É importante destacar que embora a PPP vigente não revele os conflitos decorrentes do processo de reformulação em decorrência da institucionalização, não podemos afirmar que a intenção exposta nesta proposta curricular seja uma unânime e represente a posição dos docentes efetivos que ingressaram a partir de 2014, visto que não participaram da elaboração sobre a formação a ser ofertada. Logo o percurso formativo em andamento é resultado do consenso que se foi possível chegar, mas, a partir de 2017 está em andamento discussões sobre a reformulação do PPP.

Este processo de formação diz respeito ao enfrentamento e busca coletiva de superação dos desafios tais como a herança de uma trajetória disciplinar e fragmentada, planejamento e articulação dos conteúdos a serem trabalhados nos Tempo Educativos. Neste sentido, é necessário aprofundamento dos estudos na educação do campo como forma de aperfeiçoamento da prática profissional e o fortalecimento das práticas pedagógicas nos contextos da educação do campo, dando voz aos sujeitos e suas práticas camponesas.

Reafirma-se, portanto, a visão de educação pautada no movimento Por uma Educação do Campo, que a vê como possibilidade de contribuição para a luta e demarcação de novas relações sociais que possam contribuir para o fortalecimento de uma territorialidade que expressa vida, cultura e história camponesa. Nesse território camponês, ocorrem lutas decorrentes da estrutura fundiária e dos modelos de produção engendrados historicamente no Brasil. Nesse particular, se evidencia preconceito, exploração, silêncio e invisibilidades, mas, lutas e mudanças no trato da questão - tendo a frente os movimentos sociais do campo - visando à transformação da realidade. Nesse sentido, a 
educação do campo, orientada pela perspectiva de ir para além do capital, é extremamente necessária ao propósito emancipador.

\section{Referências}

ANTUNES-ROCHA, Maria Isabel \& MARTINS, Aracy Alves (Org.) Educação do Campo: desafios para formação de professores. Belo Horizonte. Autêntica, 2009.

BRASIL. Ministério da Educação. Lei de Diretrizes e Bases da Educação Nacional: Lei9394/96. Brasília, DF, 1996.

Resolução CNE/CEB $n^{\circ}$ 01/2002. Institui as Diretrizes Operacionais para a Educação do Campo. Brasília; DF: MEC/SECAD, 2002.

. Portaria N.ำ1.374 de 3 de junho de 2003. Brasília, 2003.

. Ministério da Educação. Referências para uma Política Nacional de Educação do Campo. Caderno de subsídios. Brasília, 2003.

Resolução CNE/CEB n 01/2004. Institui as Diretrizes Operacionais para a Educação das Relações Étnico Racial e para o Ensino de História e Cultura Afro-Brasileira e Africana. Brasília; DF: MEC/SECAD, 2004.

Resolução CNE/CEB n 02/2008. Institui as Diretrizes Operacionais Complementares para a Educação do Campo. Brasília; DF: MEC/SECAD, 2008.

Decreto $\mathrm{n}^{\circ} 7.352$ de 4 de novembro de 2010. Dispõe sobre a política de Educação do Campo e o Programa Nacional de Educação na Reforma Agrária. Diário Oficial da União. 2010. Disponível em:http://www.planalto.gov.br/ccivil_03/_Ato2007-

2010/2010/Decreto/D7352.htm. Acesso em: 30 julho. 2020.

2012

Edital de seleção № 02/2012 - SESU/SETEC/SECADI/MEC. Brasília,

. Edital $n^{\circ} 2$, de 23 de abril de 2008: Chamada pública para seleção de projetos de instituições públicas de ensino superior para o PROCAMPO, Brasília, 2008.

Edital $n^{\circ}$ 9, de 29 de abril de 2009: Chamada pública para seleção de projetos de instituições públicas de ensino superior para o PROCAMPO, Brasília, 2008.

. Portaria N.ํ 1.374 de 3 de junho de 2003. Brasília, 2003.

Brasília, 2016.

NOTA TÉCNICA CONJUNTA No 3/2016/GAB/SECADI/SECADI, 
CALDART, R. Licenciatura em educação do campo e projeto formativo: qual o lugar da docência por área? In: MOLINA, M. C.; SÁ, L. M. (Org.) Licenciaturas em educação do campo: registros e reflexões a partir das experiências-piloto (UFMG; UnB; UFBA e UFS). Belo Horizonte: Autêntica Editora, 2010. - (Coleção Caminhos da Educação do Campo; 5). p. 95-121.

CALAZANS, Maria. Julieta, Costa. Para compreender a educação do estado no meio rural: Traços de uma trajetória. IN: DAMASCENO, Maria. Nobre. TERRIEN, J. (Coord.) Educação e Escola no Campo. Campinas: Papirus, 1993.

DINIZ, Diana Costa; BARROS, Anderson Henrique Costa; MACEDO, Marinalva Sousa; BOTELHO, Raimundo Edson Pinto. Relatório Rede Universitas: "Política de Expansão da Educação Superior no Brasil”; Subprojeto 07 Pesquisa: Riscos e Potencialidades da Expansão das Licenciaturas em Educação do Campo, Bacabal, 2018.

FREITAS, Luiz Carlos de. Crítica da Organização do Trabalho Pedagógico e da Didática. Papirus: Campinas, 1995.

FREITAS, Helena Costa Lopes de. As novas políticas de formação dos educadores. In: Formação do educador, Educação, demandas sócias e utopias. ljuí: Editora Unijuí, 2007.

GRUPO PERMANENTE DE TRABALHO DE EDUCAÇÃO DO CAMPO (GPT). Proposta do Plano Nacional de Formação dos Profissionais da Educação do Campo. Brasília: Secadi/MEC, 2006.

GIMONET, J.C. Praticar e compreender a Pedagogia da Alternância dos CEFFAs. Petrópolis: Vozes; Paris: AIMFR, 2007. (Coleção Alternativas Internacionais em Desenvolvimento, Educação, Família e Alternância).

ITERRA. Instituto de Educação Josué de Castro: Método Pedagógico. In: Cadernos do ITERRA, ano IV, N 9, outubro de 2004.

KOLLING, Edgar Jorge, Nery-FSC; MOLINA, Mônica Castagna (Orgs.) Por uma Educação Básica do Campo: memória. Brasília: Editora Universidade de Brasília, 1999. (Coleção por uma Educação Básica do Campo, n¹).

KUENZER, A. Z. Políticas de formação: a constituição da identidade do professor sobrante. Educação e Sociedade, n. 68, p. 163-183, 1999.

LEAL, A. A. et al. Cartografia das Licenciaturas em Educação do Campo no Brasil: expansão e institucionalização. In: MOLINA, M. C.; MARTINS, M. F. A. (orgs.). Formação de formadores: reflexões sobre as experiências da Licenciatura em Educação do Campo no Brasil. Belo Horizonte: Autêntica, 2019. p. 39-53.

LEITE, Sergio Celani. Escola rural: urbanização e políticas educacionais. São Paulo, Cortez, 1999. 
MÉSZÁROS, István. Educação para além do capital. São Paulo Boitempo, 2005.

MELO, Adriana Almeida Sales de. A mundialização da educação: consolidação do projeto neoliberal na América Latina, Brasil e Venezuela. Maceió: EDUFAL, 2004.

MOLINA, Mônica, Castagna. Expansão das Licenciaturas em Educação do Campo: desafios e potencialidades. In: Educar em Revista, Curitiba, Brasil, $n$. 55, p. 145-166, jan./mar. 2015, Editora UFPR.

Contribuições das Licenciaturas em Educação do Campo para as Políticas de formação de Educadores. Educ. Soc., Campinas, v. 38, nº 140, p.587-609, jul.-set., 2017.

MOLINA, Mônica, Castagna \& Sá, Laís Mourão (Organizadoras). Licenciaturas Em Educação do Campo: registros e reflexões a partir das experiências piloto: Autêntica, 2012.

NOSELLA, P. Uma nova educação para o meio rural: sistematização e problematização da experiência educacional das Escolas da Família Agrícola do Movimento de Educação Promocional do Espírito Santo. São Paulo: 1977. 204 p. Dissertação (Mestrado)- Pontifícia Universidade Católica de São Paulo. São Paulo, 1977.

RAMOS, Marise Nogueira. Possibilidades e desafios na organização do currículo integrado. In: CIAVATA, Maria e RAMOS, Marise (Orgs.) Ensino Médio integrado: concepção e contradições. São Paulo: Cortez, 2005.

. O projeto unitário de ensino médio sob os princípios do trabalho, ciência e da cultura. In: MST. Educação básica de nível médio nas áreas de reforma agrária: textos de estudos. Boletim da Educação, n. 11, edição especial. São Paulo: MST, 2006.

SAVIANI, Demerval. Formação de professores no brasil: dilemas e perspectivas. Poíesis Pedagógica - V.9, N.1, p. 07-19, jan/jun.2011.

TEIXEIRA E.; BERNART, M.; TRINDADE G. A. Estudos sobre a Pedagogia da Alternância no Brasil: revisão de literatura e perspectivas para a pesquisa. Educação e Pesquisa, v 34, n.2, p. 227-242, 2008.

UNIVERSIDADE FEDERAL DO MARANHÃO. Resolução n. 111/2009 CONSEPE aprova a criação do Curso do Curso de Licenciatura em Educação do Campo Ciências Agrárias/Ciências da Natureza e Matemática, São Luís, 2009.

Projeto Político Pedagógico do Curso de Licenciatura em Educação do Campo Ciências da Natureza e Matemática, São Luís, 2014.

Projeto Político Pedagógico do Curso de Licenciatura em Educação do Campo Ciências Agrárias, São Luís, 2014. 
. Edital no. 127/2009 - PROEN: Processo Seletivo Vestibular

Especial 2009 - Curso de Licenciatura em Educação do Campo, São Luis, 2009.

Edital no. 325/2010 - PROEN:Processo Seletivo Vestibular Especial 2010 - Curso de Licenciatura em Educação do Campo, São Luis, 2010.

. Edital no. 247/2014 - PROEN: Processo Seletivo Vestibular Especial 2014 - Curso de Licenciatura em Educação do Campo, São Luis, 2014.

\section{Sobre os autores}

\section{Diana Costa Diniz}

dcostadiniz@gmail.com

Graduada em Pedagogia pela Universidade Federal do Maranhão (2003), Mestre em Educação pela Universidade Federal do Maranhão (2009). Doutoranda do Programa de Pós-Graduação em Educação em Ciências e Matemática da Rede Amazônica de Educação em Ciências e Matemática REAMEC. Atualmente é professora adjunta do Curso de Licenciatura em Educação do Campo Ciências Agrárias/ Ciências da Natureza e Matemática, na Universidade Federal do Maranhão, na cidade de Bacabal no Maranhão. Exerce a docência em disciplinas da área de Fundamentos da Educação, Política, Gestão e Organização do Trabalho Pedagógico nas Escolas do Campo. Realiza estudos e pesquisas sobre Formação de professores.

\section{Evandro Ghedin}

evandroghedin@gmail.com

Professor Titular-Livre da Faculdade de Educação da Universidade Federal do Amazonas (UFAM). Possui Pós-doutorado em Didática pela Faculdade de Educação da USP (2010). É Doutor em Filosofia da Educação pela USP (2004). Mestre em Educação pela UFAM (2000). Especialista em Antropologia da Amazônia pela UFAM. Especialista em Filosofia e Existência pela Universidade Católica de Brasília (UCB). Graduado em Filosofia pela UCB (1995). Professor Permanente no PPGECEM - Rede Amazônica de Educação em Ciências e Matemática (REAMEC). Professor Permanente no PPGE-UFAM. Professor Permanente no PGEDA - Doutorado em Educação na Amazônia EDUCANORTE. Tem experiência na área de Educação, com ênfase em Educação em Ciências, atuando principalmente nos seguintes temas: Didática e Formação de Professores;Metodologia da Pesquisa em Educação; Epistemologia; Educação em ciências; Filosofia da Educação. Atuou na Educação Básica da Rede Pública e Privada por 5 anos. É professor Universitário desde 1997. É autor de diversos livros e artigos científicos na área da Educação. 